\title{
An iterative numerical method for determination of temperature-dependent friction coefficients in thermomechanical model analysis of cold bolt forging
}

\author{
U. Ince • M. Güden
}

Received: 7 November 2012 / Accepted: 3 February 2013 /Published online: 20 February 2013

(C) Springer-Verlag London 2013

\begin{abstract}
A set of temperature-dependent friction coefficients was developed to increase the accuracy of finite element (FE) simulations of cold bolt forging. The initially attained friction coefficients at different temperatures were calibrated with the iterations between the experimental and thermomechanical model extrusion test loads. The constant friction coefficient and the determined set of friction coefficients as function of temperature were then implemented to the simulations of the cold bolt-forging processes. Further calibrations and model validations were made based on the temperature measurements of the workpiece in the actual bolt-forging processes. To show the advantages of developed temperature-dependent friction coefficients, the loads of four different bolt-forging processes were compared with the thermomechanical model loads calculated using the constant friction and temperature-dependent friction coefficients. The modeling results indicated that the use of temperature-dependent friction coefficients in the FE simulations resulted in nearer temperature distributions and the loads of the workpiece during forging as compared with the use of a constant friction coefficient.
\end{abstract}

Keywords Friction $\cdot$ Cold forging $\cdot$ Bolt $\cdot$ Numerical simulation $\cdot$ Fastener

\footnotetext{
U. Ince 35620 Çiğli, İzmir, Turkey

\section{Güden}

Dynamic Testing and Modeling Laboratory, Izmir Institute of Technology, Gulbahce Koyu, Urla, Izmir, Turkey

\section{Güden ( $\square)$}

Department of Mechanical Engineering, Izmir Institute of Technology, Gulbahce Koyu, Urla, Izmir 35430, Turkey

e-mail: mustafaguden@iyte.edu.tr
}

Norm Fasteners Co, Atatürk Organize Sanayi Bölgesi 10007,

\section{Introduction}

The friction between workpiece and tool in cold forging directly affects tool stress, material flow, internal defect formation, forging loads, and energy requirements. Previous studies of friction models were mostly based on ring compression and forward and backward rod extrusion tests in conjunction with the inverse analyses of the experimental and numerical simulation results. Hayhurst and Chan [1] proposed a two-parameter friction model (the Coulomb friction model and friction factor yield stress model), which was calibrated by cylindrical and ring compression tests. Behrens and Schafstall [2], using the neural network technique, determined the dependency of friction on contact parameters. The insertion of local friction parameters in the finite element model calculations resulted in higher degree of simulation accuracies. Cho and Altan [3] introduced an inverse analysis technique to determine the friction at toolworkpiece interface at elevated temperatures using the geometrical changes of deformed samples. The technique was capable of determining the flow stress and friction factor simultaneously from one set of tests. Wang et al. [4] reported a real-time measurement technique of evaluating the friction in a ring test. Cora et al. [5] investigated the effect of constant and variable friction coefficients in cold forging. The constant friction coefficient was shown to not able to capture the actual friction conditions. Tan et al. [6] investigated the friction stresses under different pressures and reported a linear relationship between normal pressure and friction stress. Dubois et al. [7] conducted upsetting-sliding test between 25 and $150{ }^{\circ} \mathrm{C}$ on a zinc phosphate/soap-coated carbon steel to simulate the characteristic contact conditions in a cold heading sequence composing of wire drawing and direct extrusion. The friction coefficient decreased from 0.071 to 0.04 when the temperature 
Fig. 1 QST36-3 steel samples after and before forward extrusion test; specimens a $25 \mathrm{~mm}$, b $30 \mathrm{~mm}$, and c $35 \mathrm{~mm}$ in length
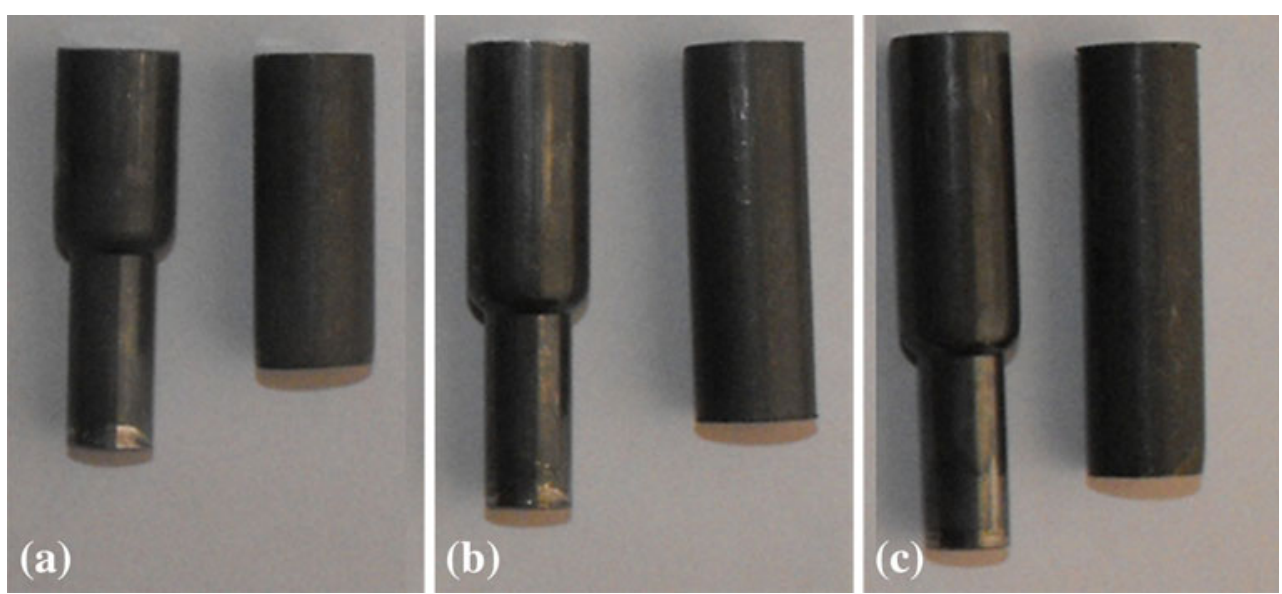

increased from 25 to $150{ }^{\circ} \mathrm{C}$. The drop in the friction coefficient at intermediate temperatures was attributed to the softening and/or melting of sodium and zinc stearates. Saiki et al. [8] investigated the plastic deformation of zinc phosphate-coated specimens and showed that the friction between die and specimen varied with the die geometry and temperature.

In the present study, an iterative numerical method was proposed for the determination of the temperaturedependent friction coefficients in the thermomechanical model analysis of cold bolt forging in order to increases the accuracy of the simulations. The method was based on the determination of friction coefficients as function temperature by means of forward rod extrusion tests and thermomechanical simulations. The surface temperatures of workpieces in actual cold bolt-forging processes were measured using a thermal camera to validate the thermomechanical model. Finally, the forging loads of four different bolt-forging processing, M $8 \times 28$ plastic screw, $\mathrm{M} 8 \times 16$ DIN 6921, M $8 \times 30$ DIN 6921, and M $8 \times 65$ convex head, were measured and compared with those of numerical forging loads of the constant and variable friction coefficients.

\section{Materials and testing}

Forward rod extrusion experiments with the reduction ratios of $48 \%$ were performed using zinc phosphate/soap-coated cylindrical QST36-3 steel samples; 25, 30 and $35 \mathrm{~mm}$ in length and $9.73 \mathrm{~mm}$ in diameter, as depicted in Fig. 1a-c. The zinc phosphate coating prevents the metal to metal contact and the metal soap reduces the friction between tool and workpiece $[9,10]$. Before the extrusion experiments, the die, punch and workpiece were either heated to 120 or $180{ }^{\circ} \mathrm{C}$ in a furnace. The surface temperatures of the die, punch, and workpiece were measured in the furnace using a thermal camera before they were taken from the furnace for the extrusion tests. The time elapsed between the start of extrusion test and the moment at which the die, punch, and workpiece taken from the furnace was about $40 \mathrm{~s}$. The extrusion tests were performed in a Schimadzu mechanical testing machine at the displacement rate of $0.05 \mathrm{mms}^{-1}$. The final displacement attained in the extrusion tests was $12 \mathrm{~mm}$. The displacement was calculated by subtracting the test machine displacement from the total displacement. The machine compliance used to calculate machine displacement was determined in a separate experiment by compressing the compression test platens until about a final prescribed load. Finally, each group of extrusion tests was repeated at least three times and the load values were determined as the average of three experiments.

The emissivity of zinc phosphate-coated QST36-3 steel, which was required in the thermal camera measurements, was determined by applying the following procedure. A black tape with a known emissivity, 0.96, was stuck on the workpiece. The temperature of the black tape with the emissivity number of 0.9 varied between 28.84 and $29.35^{\circ} \mathrm{C}$ and the temperature of the workpiece between 28.01 and $28.7^{\circ} \mathrm{C}$. The emissivity of the workpiece was then reduced until the temperature of the workpiece became nearly equal to that of the black tape. Using the aforementioned procedure, the emissivity of the workpiece was found to be 0.79 .
Fig. 2 Axisymmetric extrusion die model

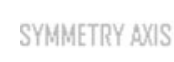

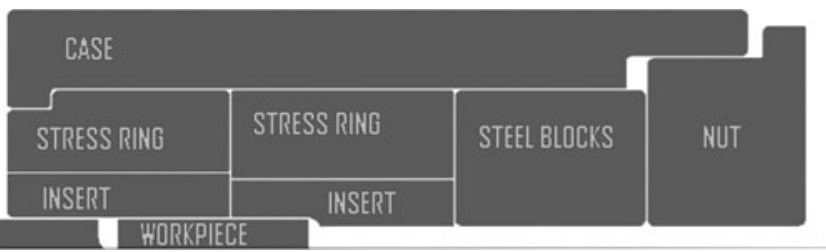




\section{Modeling, material model parameters, and model validation}

The extrusion tests simulations (implicit) were implemented in Simufact ${ }^{\circledR}$. Three-dimensional solid models of the extrusion die and punch were created in Catia V5 software. The axisymmetric extrusion die model is shown in Fig. 2 and composed of stress ring, insert, space holder, case, steel blocks, and locking nut. The extrusion die and workpiece were modeled using Quad-4 solid elements. The size and number of the elements used in the extrusion die models were sequentially $0.2 \mathrm{~mm}$ and 6,393 for the inserts, $0.4 \mathrm{~mm}$ and 2,407 for the punch, $0.4 \mathrm{~mm}$ and 2,894 for the front stress ring, $0.4 \mathrm{~mm}$ and 3,188 for the back stress ring, $0.8 \mathrm{~mm}$ and 2,281 for the case, $0.4 \mathrm{~mm}$ and 4,165 for the steel blocks, and $0.8 \mathrm{~mm}$ and 1,204 for the nut. The workpiece was modeled with $0.2 \mathrm{~mm}$ element size and the numbers of elements used in 25, 30, and $35 \mathrm{~mm}$ long workpieces were sequentially $3,140,3,777$, and 4,406.

The die components were modeled with an elastic material model. The simulations were performed in accord with the extrusion tests: the heated extrusion die, punch, and workpiece were waited in open atmosphere for $40 \mathrm{~s}$ before the start of the simulations of the extrusion tests. The die components except inserts were made of 1.2344 tool steel. The Poisson's ratio and mass density of 1.2344 tool steel were 0.23 and $7.85 \mathrm{~g} \mathrm{~cm}^{-3}$, respectively. The elastic modulus, thermal conductivity, and heat capacity of 1.2344 tool steel were provided by the manufacturer data sheet (Uddeholms AB). The thermal expansion coefficient of 1.2344 tool steel was taken as $1.17 \times 10^{-5}{ }^{\circ} \mathrm{C}^{-1}$ and increased with increasing temperature with a coefficient of $3.01 \times 10^{-9}{ }^{\circ} \mathrm{C}^{-1}$. The thermal conductivity, thermal expansion coefficient and heat capacity of the insert material, WC/Co (19\% Co) PM tool steel, were taken from the manufacturer data sheet (Ceratizit S.A Company). The elastic modulus, Poisson's ratio and mass density of $\mathrm{WC} / \mathrm{Co} \mathrm{PM}$ tool steel were $496 \mathrm{GPa}, 0.24 \mathrm{~g} \mathrm{~cm}^{-3}$, and $12.950 \mathrm{gcm}^{-3}$, respectively. A Coulomb friction was applied between the workpiece and die in the models and the mechanical and friction heat generation conversion factor was taken as 0.9 . The Coulomb friction is given as

$\sigma_{t}=-\mu \sigma_{n} \frac{v_{s}}{\left|v_{s}\right|}$

where, $\sigma_{t}$ is the friction stress, $\mu$ is the friction coefficient, $\sigma_{n}$ is the contact pressure, and $v_{s}$ is the sliding velocity.

The workpieces were modeled using the piecewise linear plasticity model. The tensile true stress-strain curve of QST36-3 steel used in the extrusion experiments and $20 \mathrm{MnB} 4$ steel used in the actual bolt-forging were determined between 20 and $400{ }^{\circ} \mathrm{C}$ at the strain rates of 1,10 , and $50 \mathrm{~s}^{-1}$. The curves were directly entered into the
Simufact. Figures $3 \mathrm{a}$ and $\mathrm{b}$ show true stress-true plastic strain curves of QST36-3 and 20MnB4 steel at various temperatures and strain rates, respectively. The Poisson's ratio and mass density of QST36-3 and 20MnB4 steel were taken as 0.29 and $7.85 \mathrm{~g} \mathrm{~cm}^{-3}$, respectively. The elastic modulus of QST36-3 and 20MnB4 steel was taken as function of temperature, $212 \mathrm{GPa}$ at $20{ }^{\circ} \mathrm{C}$ with a temperature reduction coefficient of $0.096 \mathrm{GPa}^{\circ} \mathrm{C}^{-1}$. The thermal expansion coefficient of QST36-3 and 20MnB4 steel was $1.19 \times$ $10^{-5}{ }^{\circ} \mathrm{C}^{-1}$ and increased with increasing temperature with a coefficient of $5.6 \times 10^{-9}{ }^{\circ} \mathrm{C}^{-1}$.

The experimental extrusion load-displacement curves were compared to the simulation load-displacement curves of constant and temperature-dependent friction coefficients. The temperature-dependent friction coefficients, which
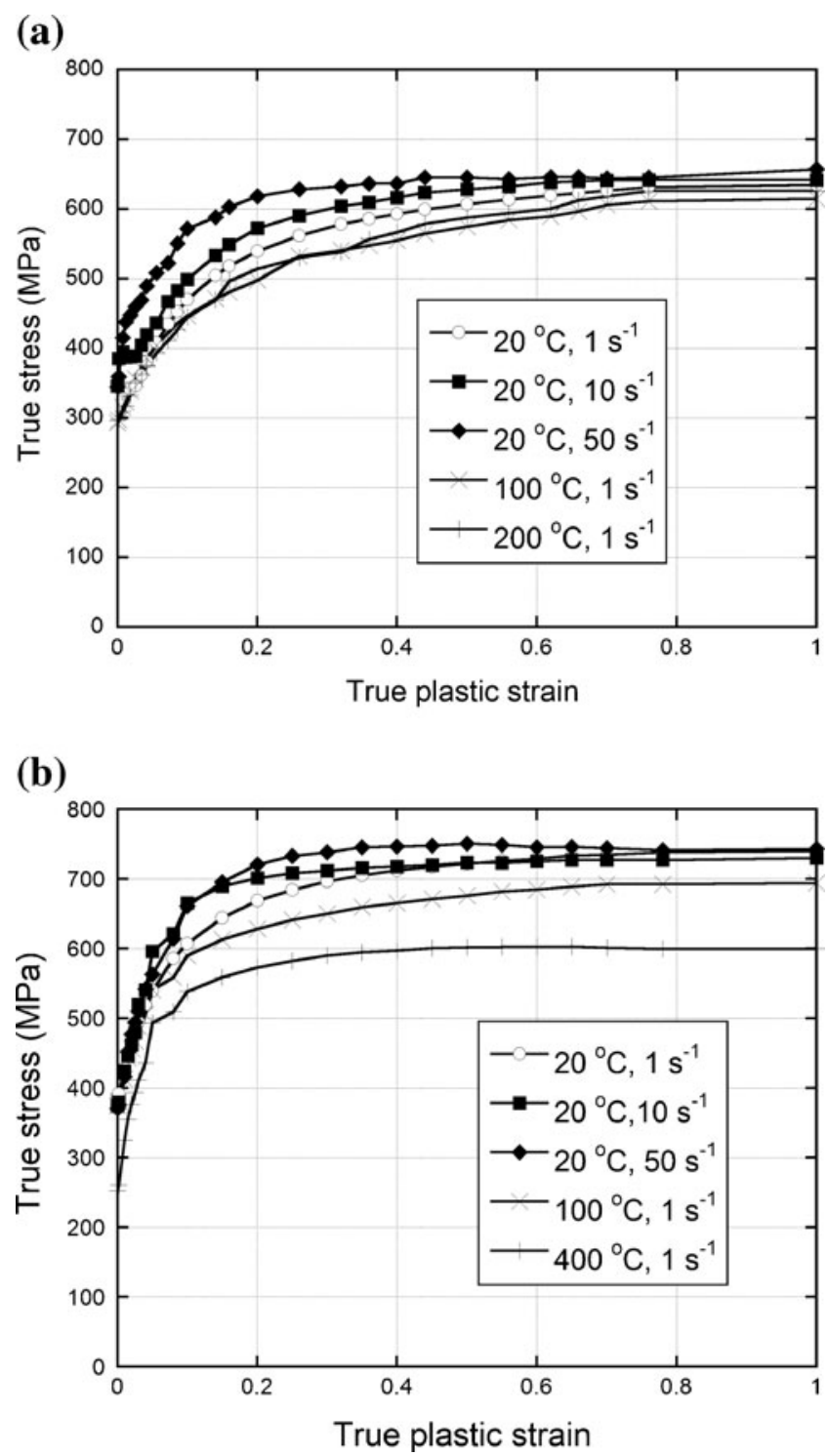

Fig. 3 True stress-true plastic strain curves of a QST36-3 and b $20 \mathrm{MnB} 4$ steel at various strain rates and temperatures 
Fig. 4 Thermal camera pictures and the variation of the temperature of extrusion die, punch and workpiece (in the furnace) heated to $\mathbf{a} 120$ and $\mathbf{b}$ $180{ }^{\circ} \mathrm{C}$ (the line of measurements are shown by arrows) (a)
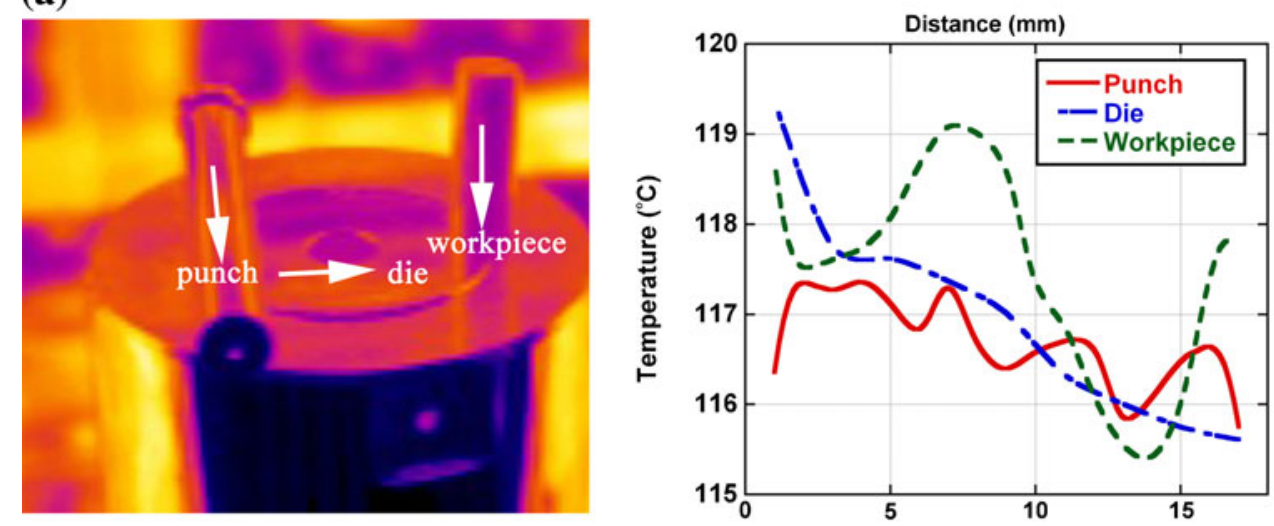

(b)
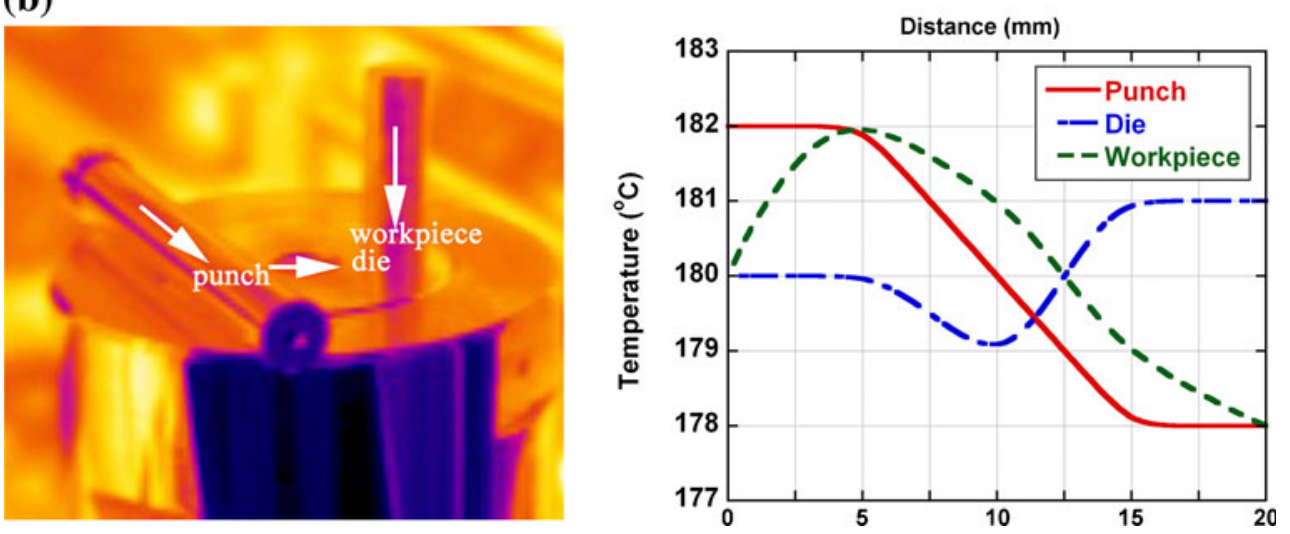

(a)
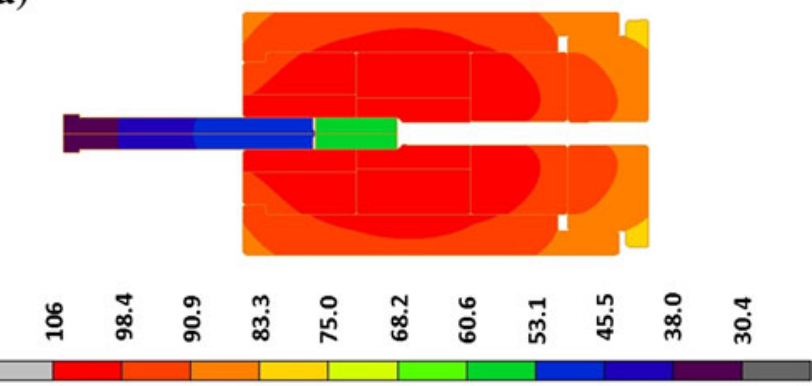

Temperature $\left({ }^{\circ} \mathrm{C}\right)$

(b)

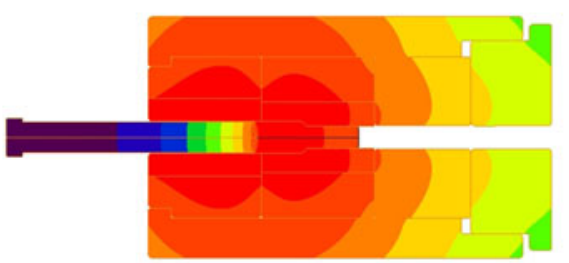

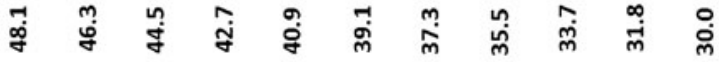

Temperature $\left({ }^{\circ} \mathrm{C}\right)$

Fig. 5 The temperature distribution of the extrusion die, punch, and workpiece heated to $120^{\circ} \mathrm{C}$; a after $40 \mathrm{~s}$ taken from the furnace and $\mathbf{b}$ after the extrusion test (25-mm sample) nearly approximate the experimental load-displacement curves in the simulations, were identified. The numerically determined temperature-dependent friction coefficients were then implemented to the actual bolt-forging process. M $8 \times 20$ circular head and M10 $\times 20$ Inbus DIN 912 cold bolt-forging

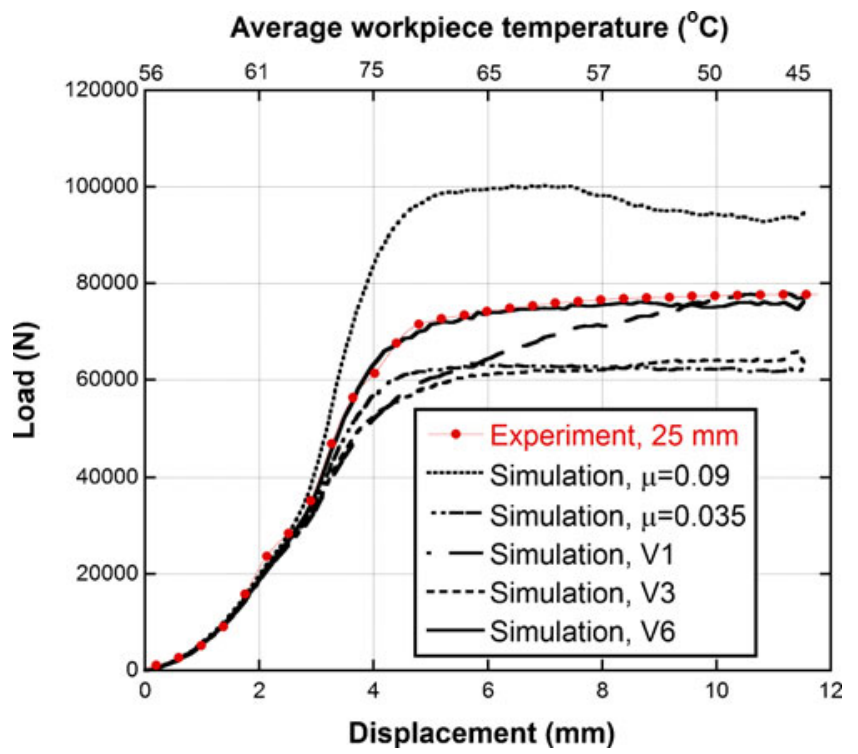

Fig. 6 Experimental and numerical extrusion load-displacement curves with constant and temperature-dependent friction coefficients, $25 \mathrm{~mm}$ long sample heated to $120^{\circ} \mathrm{C}$ 
Table 1 The friction coefficient variation with temperature in various scenarios

\begin{tabular}{|c|c|c|c|c|c|c|c|c|}
\hline $\mathrm{T}\left({ }^{\circ} \mathrm{C}\right)$ & V1 & V2 & V3 & V4 & V5 & V6 & V7 & V8 \\
\hline 25 & 0.090 & 0.090 & 0.090 & 0.090 & 0.090 & 0.090 & 0.090 & 0.090 \\
\hline 50 & 0.070 & 0.040 & 0.040 & 0.034 & 0.040 & 0.065 & 0.065 & 0.065 \\
\hline 60 & - & - & 0.035 & 0.031 & - & 0.060 & 0.060 & 0.060 \\
\hline 70 & 0.035 & 0.035 & 0.030 & 0.028 & 0.050 & 0.056 & 0.055 & 0.055 \\
\hline 75 & 0.025 & 0.025 & 0.025 & 0.025 & 0.045 & 0.050 & 0.050 & 0.050 \\
\hline 90 & & & & & & 0.045 & 0.045 & 0.045 \\
\hline 105 & & & & & & & 0.040 & 0.040 \\
\hline 200 & & & & & & & 0.035 & 0.035 \\
\hline 300 & & & & & & & & 0.0475 \\
\hline 400 & & & & & & & & 0.060 \\
\hline
\end{tabular}

processes were performed in a commercial SP300 horizontal crank press in order to compare the measured and numerically determined temperature distributions. $\mathrm{M} 8 \times 28$ plastic screw, M8× 16 DIN 6921, M8×30 DIN 6921, and M8×65 convex head bolt-forging were performed in a commercial JBF $13 \mathrm{~B} 6 \mathrm{~S}$ horizontal crank press. The maximum forging loads at each station of JBF 13B6S horizontal crank press were measured using piezoelectric sensors. The sensors were calibrated and fixed on the dies in each station. The same numerical model and material model parameters of extrusion test simulations were also implemented in the modeling of the bolt-forging processes.

\section{Results and discussion}

Figure $4 \mathrm{a}$ and $\mathrm{b}$ show thermal camera pictures and the variation of the temperature of the punch, die and workpiece heated to 120 and $180^{\circ} \mathrm{C}$, respectively. The temperature was measured on the punch, die, and workpiece separately,

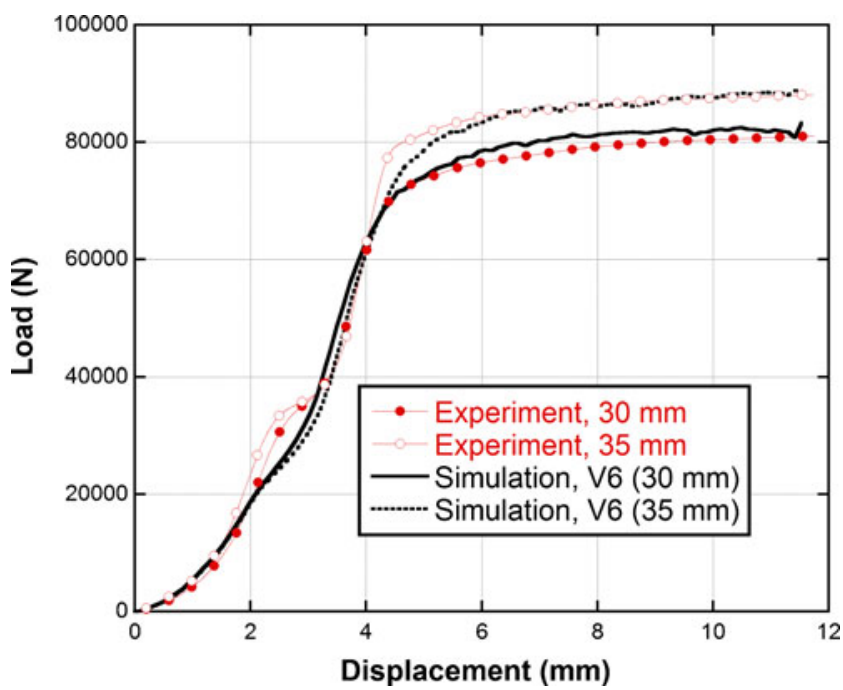

Fig. 7 Experimental and numerical extrusion load-displacement curves of 30 and $35 \mathrm{~mm}$ long samples long sample heated to $120^{\circ} \mathrm{C}$ along the lines shown by the arrows in Fig. $4 a$ and $b$. The camera pictures were taken just before the die, punch, and workpiece taken from the furnace for the extrusion tests. The temperature of the punch, die, and workpiece varies between $115.5-119.5$ and $178-182{ }^{\circ} \mathrm{C}$ at the furnaceheating temperature of 120 and $180^{\circ} \mathrm{C}$ as shown in Fig. $4 \mathrm{a}$ and $\mathrm{b}$, respectively. The simulation temperature distribution of the extrusion die, punch and workpiece (25 mm) heated to $120{ }^{\circ} \mathrm{C}$ is shown in Fig. 5a before the extrusion test but after $40 \mathrm{~s}$ taken from the furnace. As seen in Fig. 5a, the temperature of the workpiece decreases to $60{ }^{\circ} \mathrm{C}$ and the temperature of the punch to $30-50{ }^{\circ} \mathrm{C}$ after

(a)
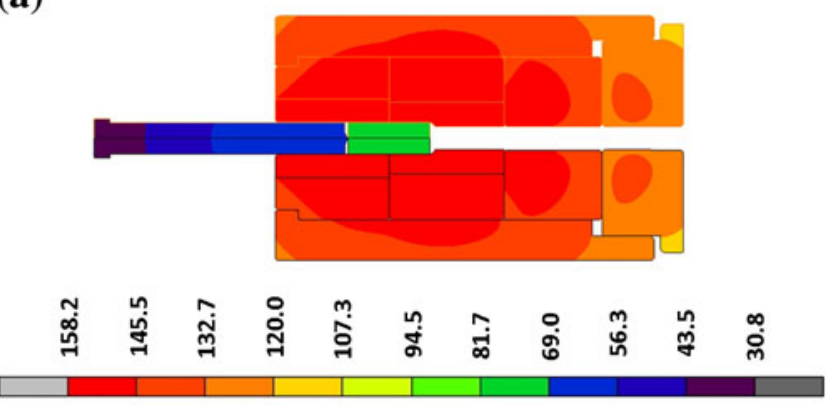

Temperature $\left({ }^{\circ} \mathrm{C}\right)$

(b)

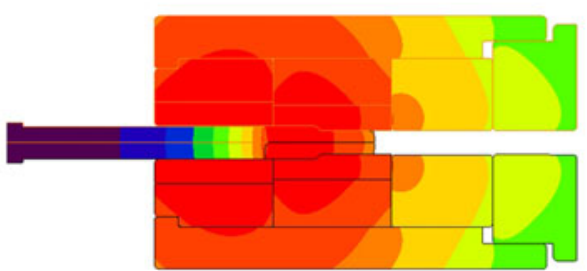

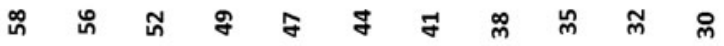

Temperature $\left({ }^{\circ} \mathrm{C}\right)$

Fig. 8 The temperature distribution of the extrusion die, punch and workpiece heated to $180{ }^{\circ} \mathrm{C}$ a after $40 \mathrm{~s}$ taken from the furnace and $\mathbf{b}$ after extrusion (25-mm sample) 


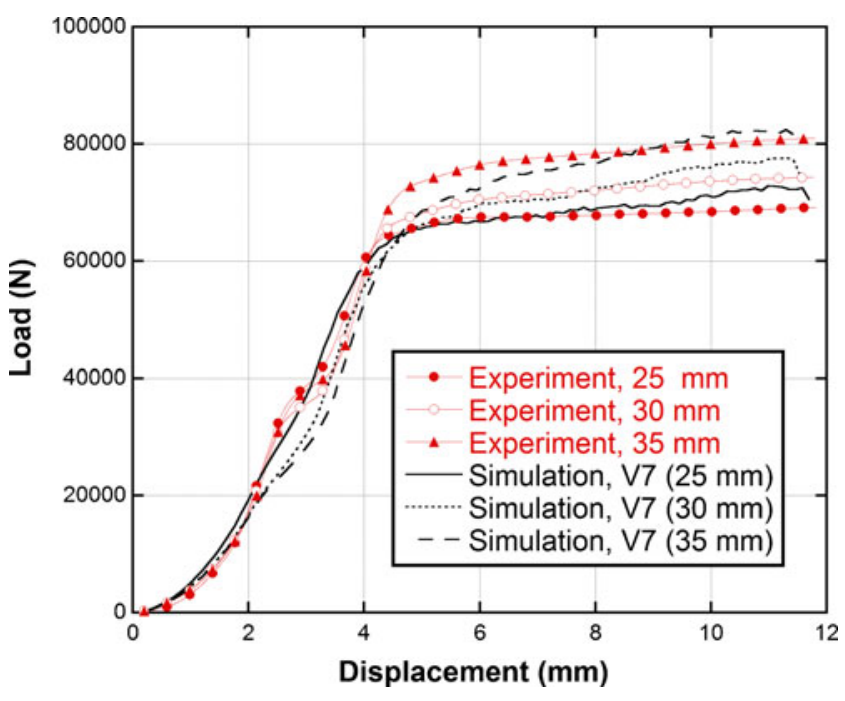

Fig. 9 Experimental and simulation extrusion load-displacement curves of 20,30 and $35 \mathrm{~mm}$ long samples heated to $180{ }^{\circ} \mathrm{C}$

$40 \mathrm{~s}$. The simulation temperature distribution of the extrusion die, punch and workpiece after the extrusion test is shown in Fig. $5 \mathrm{~b}$ for comparison. After the extrusion, the temperature of the workpiece decreases to $40{ }^{\circ} \mathrm{C}$.

The experimental load-displacement curve of $25 \mathrm{~mm}$ long specimen heated to $120^{\circ} \mathrm{C}$ is shown in Fig. 6 together with numerically determined load-displacement curves using constant friction coefficient $(0.09$ and 0.035$)$ and temperature-dependent friction coefficients. The constant

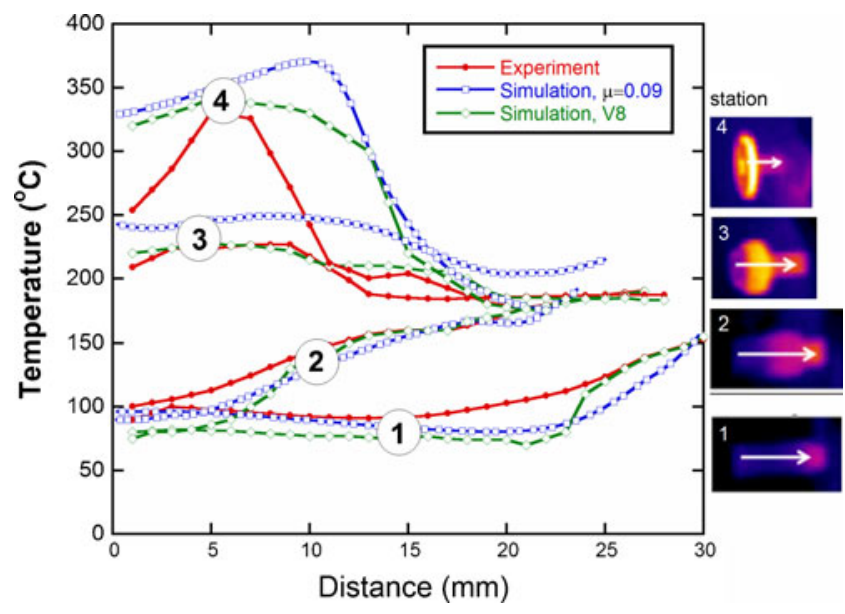

Fig. 11 The experimental (thermal camera) and numerical (constant and V8 set of friction coefficients) temperatures at 4 stations of M $8 \times 20$ circular head bolt forging (the start and end of the arrows show the beginning and end of temperature measurement and the numbers show the station number)

friction coefficient of 0.09 yields higher, while 0.035 lower extrusion loads than those of experiment. Several different temperature-dependent friction coefficient sets coded as V1, V2, V3, V4, V5, and V6 in Table 1 are developed and implemented. Initially, V1 set of friction coefficients was arbitrarily attained and implemented to the model and then sequentially the friction coefficient set was modified by trial and error until the numerical load-displacement curve
Fig. 10 The simulation temperature distribution of M8 $\times 20$ circular head bolt forging with $\mathbf{a}$ constant and $\mathbf{b}$ temperature-dependent friction coefficients

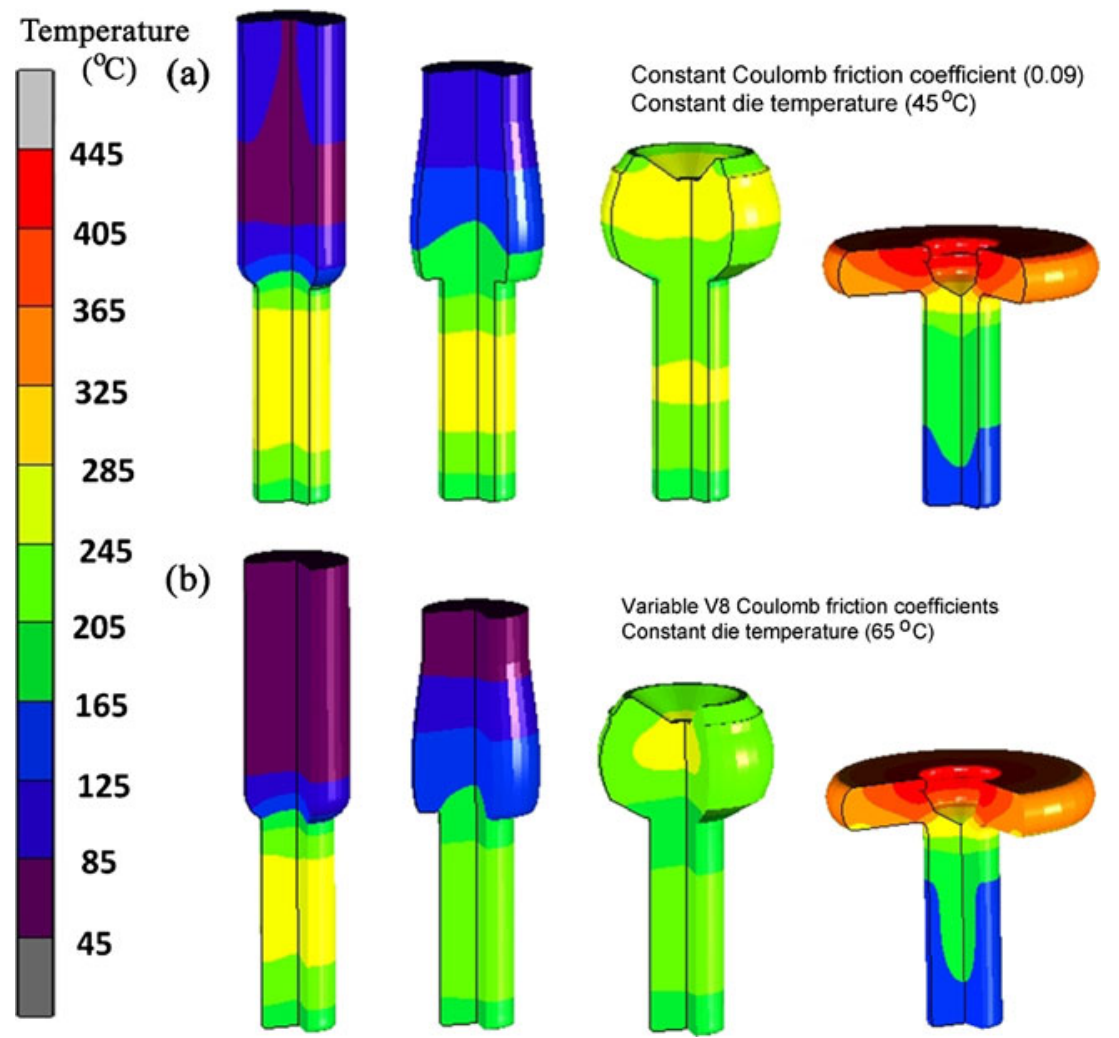




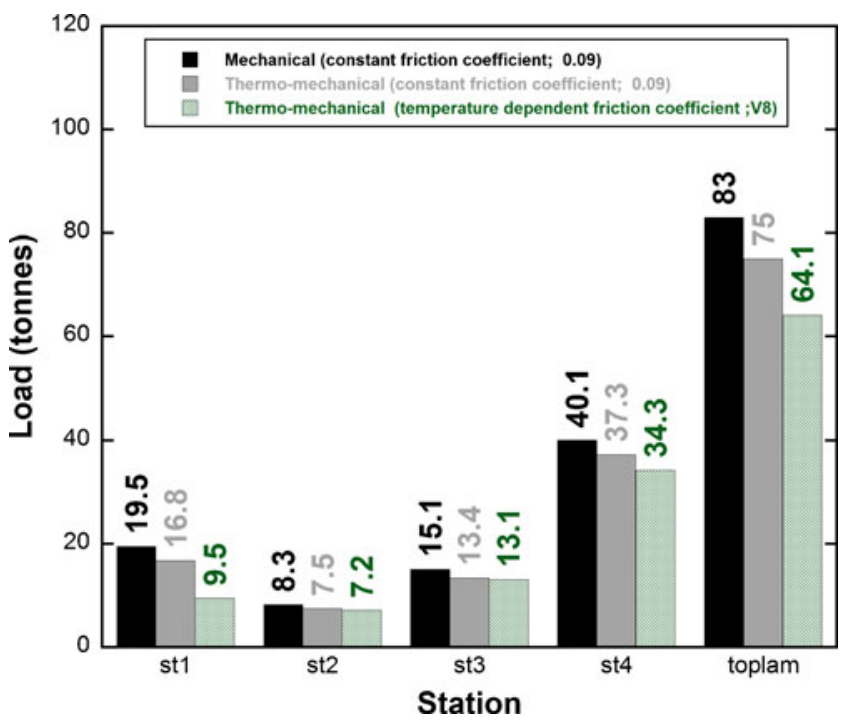

Fig. 12 The numerical press loads of $M 8 \times 20$ circular head bolt forging for constant and temperature-dependent friction coefficients, mechanical, and thermomechanical analysis

attained an acceptable correlation with the experimental load displacement curve (the difference less than $10 \%$ ). The load values of V6 set of friction coefficients show the least deviation from the experimental load values as shown in Fig. 6. The extrusion simulations of 30 and $35 \mathrm{~mm}$ long samples were implemented using V6 set of friction coefficients. The experimental and simulation load-displacement curves of 30 and $35 \mathrm{~mm}$ long workpieces also show very close agreements with each other (Fig. 7). The temperature distributions of the extrusion die, punch and workpiece heated to $180{ }^{\circ} \mathrm{C}$, before and after the extrusion test, are shown in Fig. $8 \mathrm{a}$ and b, respectively. The temperature of the workpiece decreases to $50{ }^{\circ} \mathrm{C}$ after the extrusion test.

In order to simulate the extrusion of the samples heated to $180{ }^{\circ} \mathrm{C}$, the friction coefficients of set V6 is extended to include the friction coefficient at $200{ }^{\circ} \mathrm{C}$ and new set is coded as V7 (Table 1). The simulation extrusion load-displacement curves of 25,30 , and $35 \mathrm{~mm}$ long samples using V7 set of friction coefficients are shown in Fig. 9 together with those of experiments. Acceptable agreements are seen between experimental and simulated load-displacement curves of the extruded workpiece heated to $180{ }^{\circ} \mathrm{C}$. The maximum difference between numerical and experimental loads is $\sim 7 \%$.

The simulations of four-station M $8 \times 20$ circular head and M10 $\times 20$ Inbus DIN 912 bolt-forging processes were performed using a constant die temperature in order to simulate the actual forging process, in which after the certain numbers of productions the die temperature reached steady state (constant tool temperature). Figure 10a shows the temperature distribution of $\mathrm{M} 8 \times 20$ circular head bolt forging, using the constant friction coefficient of 0.09 and the constant die temperature of $45^{\circ} \mathrm{C}$. As seen in Fig. 10a, the temperature of the workpiece rises above $400{ }^{\circ} \mathrm{C}$ in the last station. As zinc phosphate coating layer is expected to break down above $200{ }^{\circ} \mathrm{C}$ [11], an increase in the friction coefficient is
Fig. 13 The temperature distribution of $\mathrm{M} 10 \times 20 \mathrm{DIN}$ 912 Inbus bolt forging with a constant and $\mathbf{b}$ temperaturedependent friction coefficients
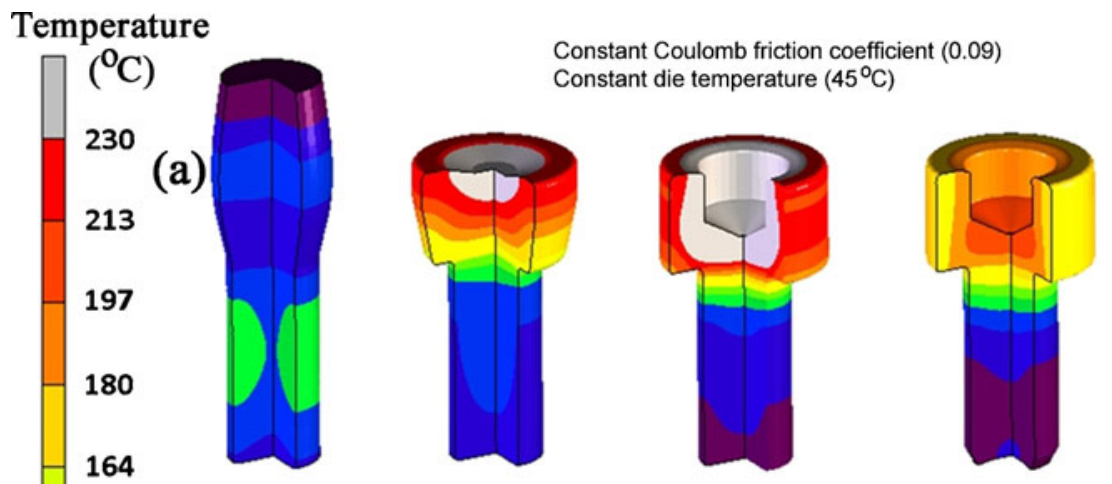

147

131

(b)

114

98

81

65

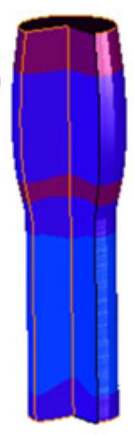

Variable $\mathrm{V} 8$ Coulomb friction coefficients Constant die temperature $\left(65^{\circ} \mathrm{C}\right)$

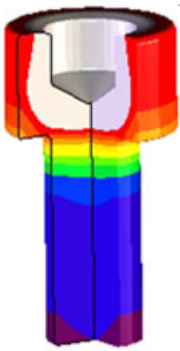

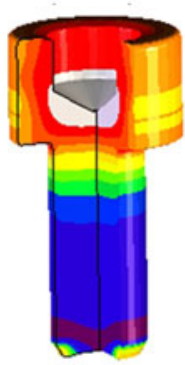


naturally expected at elevated temperatures. The simulation and experimental temperature variations of the workpiece at each station are graphically shown in Fig. 11. Constant friction coefficient simulations result in higher temperatures than the measured temperatures (camera) particularly at the third and fourth stations where the workpiece deformations are severe and the deformation temperatures are relatively high. To approximate the measured temperatures at the stations, friction coefficients of 0.0475 and 0.06 at 300 and $400{ }^{\circ} \mathrm{C}$, after several trials and errors, are attained to V7 and new set of friction coefficients is coded as V8 (Table 1). The analysis of the temperature distribution of the workpiece at the stations using V8 set of friction coefficients and the die temperature of $65^{\circ} \mathrm{C}$ are shown in Fig. 10b. The temperature distribution of V8 set of friction coefficients show higher degree of correlations with the measured temperature

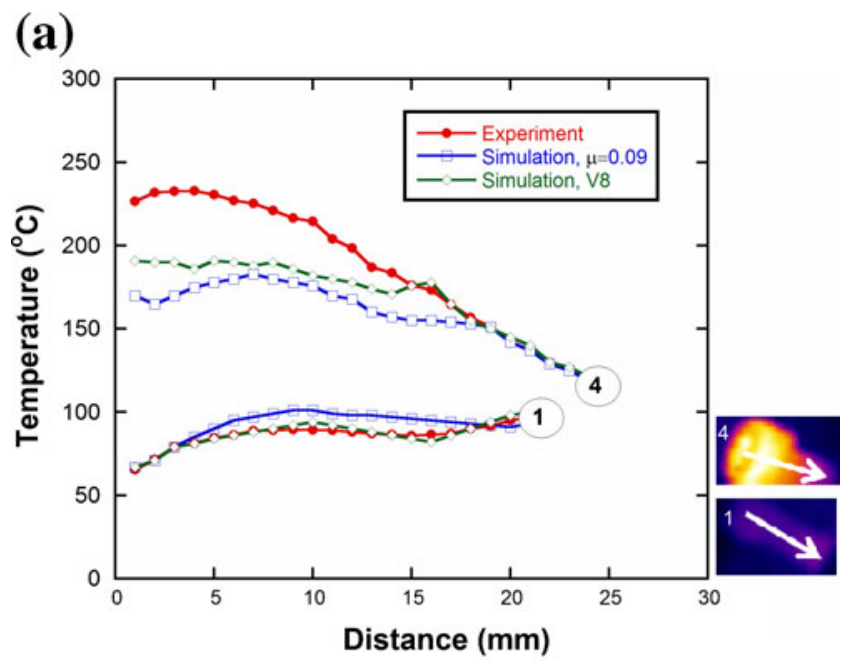

(b)

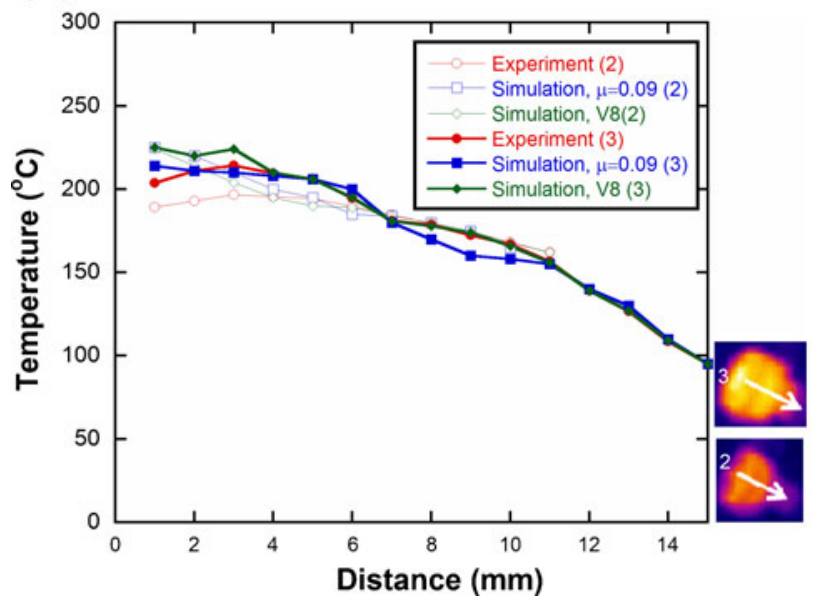

Fig. 14 The experimental (thermal camera) and numerical (constant and V8 set of friction coefficients) temperatures through stations of M10 $\times 20$ DIN 912 Inbus bolt forging (a) stations 1 and 4 and (b) 2 and 3 (the start and end of the arrow show the beginning and end of temperature measurement and the numbers show the station number) distribution, particularly in the fourth station than that of the constant friction coefficient as shown in Fig. 11. Figure 12 shows the calculated loads in each station using constant friction mechanical and constant and temperature-dependent friction coefficient thermomechanical analysis for comparison. Temperature-dependent friction coefficient thermomechanical analysis results in relatively lower total forging loads than the constant friction mechanical and thermomechanical analysis. The difference between mechanical and thermomechanical analysis, as is expected, increases with increasing workpiece temperature. The decrease in total forging load as compared with mechanical analysis is about $22 \%$ when the temperature-dependent friction coefficients are used in the thermomechanical analysis, while $10 \%$ decrease in load merely results from the use of thermomechanical analysis.

Figure 13a shows the temperature distribution of a 4station $\mathrm{M} 10 \times 20$ Inbus bolt forging using constant friction coefficient of 0.09 and the constant die temperature of $45^{\circ} \mathrm{C}$ and Fig. 13b shows the temperature distribution using V8 set of friction coefficients and the constant die temperature of $65{ }^{\circ} \mathrm{C}$. The maximum temperatures in both simulations are about $250{ }^{\circ} \mathrm{C}$. Figure 14a shows the temperature distributions of the first and fourth stations using the constant friction coefficient of 0.09 and the constant die temperature of $45^{\circ} \mathrm{C}$ and Fig. $14 \mathrm{~b}$ shows the temperature distribution of second and third stations using V8 set of friction coefficients and the constant die temperature of $65^{\circ} \mathrm{C}$. The temperature distributions of the stations using V8 set of friction coefficients and the die temperature of $65^{\circ} \mathrm{C}$ show again higher degree of correlations with those of experiments than using the constant friction coefficient of 0.09 and the constant die

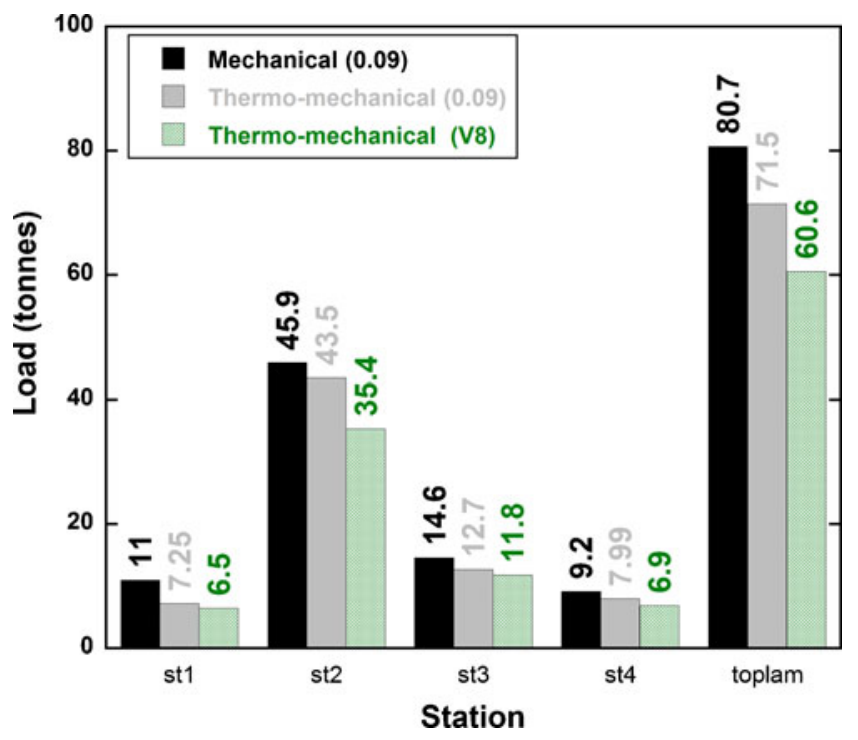

Fig. 15 The numerical press loads of M10 $\times 20$ DIN 912 Inbus forging for constant and temperature-dependent friction coefficients with mechanical and thermo mechanical analysis 
Fig. 16 The equivalent plastic strain distribution, forging loads, and total forging load of $\mathrm{M} 8 \times 28$ plastic screw forging process

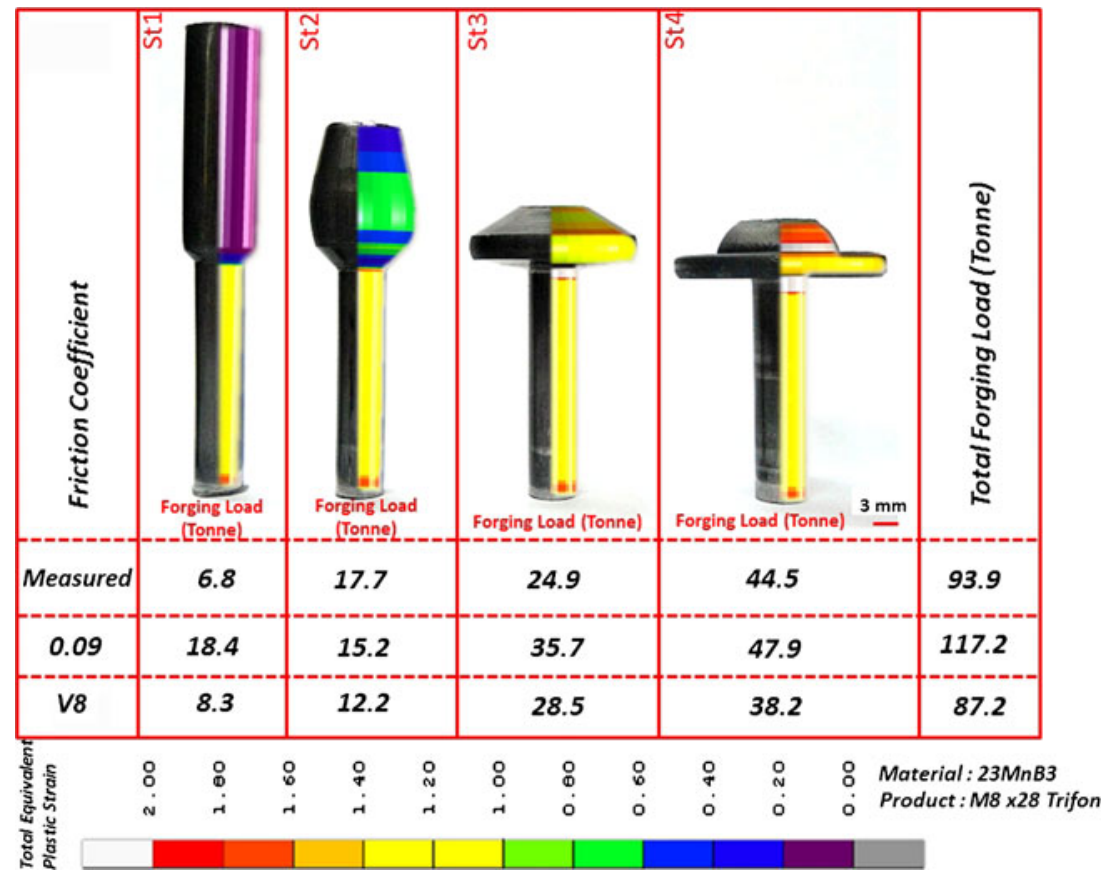

temperature of $45^{\circ} \mathrm{C}$. As in the M $8 \times 20$ circular head bolt forging, the variable friction coefficient in M10 $\times 20$ Inbus bolt forging results in lower total forging load than the constant friction mechanical and thermomechanical analysis as shown in Fig. 15. The decrease in total forging load of temperature-dependent friction coefficient thermomechanical analysis as compared with mechanical analysis is as much as $25 \% ; 11 \%$ of the decrease results from the use of thermomechanical analysis. These results indicate that the implementation of temperature-dependent friction coefficient in thermomechanical analysis yields lower forging loads than that of constant friction, particularly at the stations of severe plastic deformation.
In order to validate the fidelity of the developed thermomechanical model, the constant friction coefficient and the determined set of friction coefficients were implemented in the thermomechanical analyses of M8 $\times 28$ plastic screw, M $8 \times 16$ DIN 6921, M8 $\times 30$ DIN 6921, M8 $\times 65$ convex head boltforging processes. In the simulations, the maximum forging loads were determined using 0.09 constant friction coefficient, V8 set of temperature-dependent friction coefficients and $65^{\circ} \mathrm{C}$ constant die temperature. The results of numerical total plastic strain distribution and measured and numerically determined station forging loads and total forging loads are sequentially shown in Figs. 16, 17, 18, and 19 for M8 $\times 28$ plastic screw, M8 $\times 16$ DIN 6921, M8 $\times 30$ DIN 6921 and M8 $\times 65$ bolt-
Fig. 17 The equivalent plastic strain distribution, forging loads, and total forging load of M8×16 DIN 6921 forging process

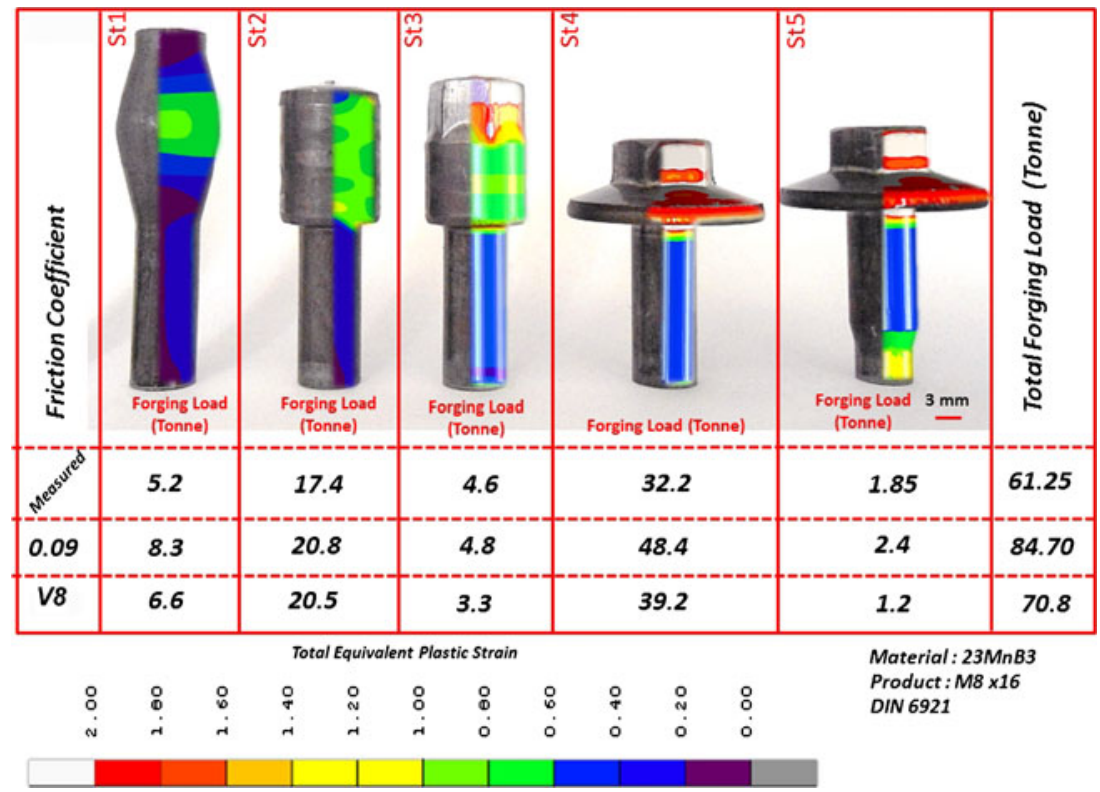


Fig. 18 The equivalent plastic strain distribution, forging loads, and total forging load of M8 $\times 30$ DIN 6921 forging process

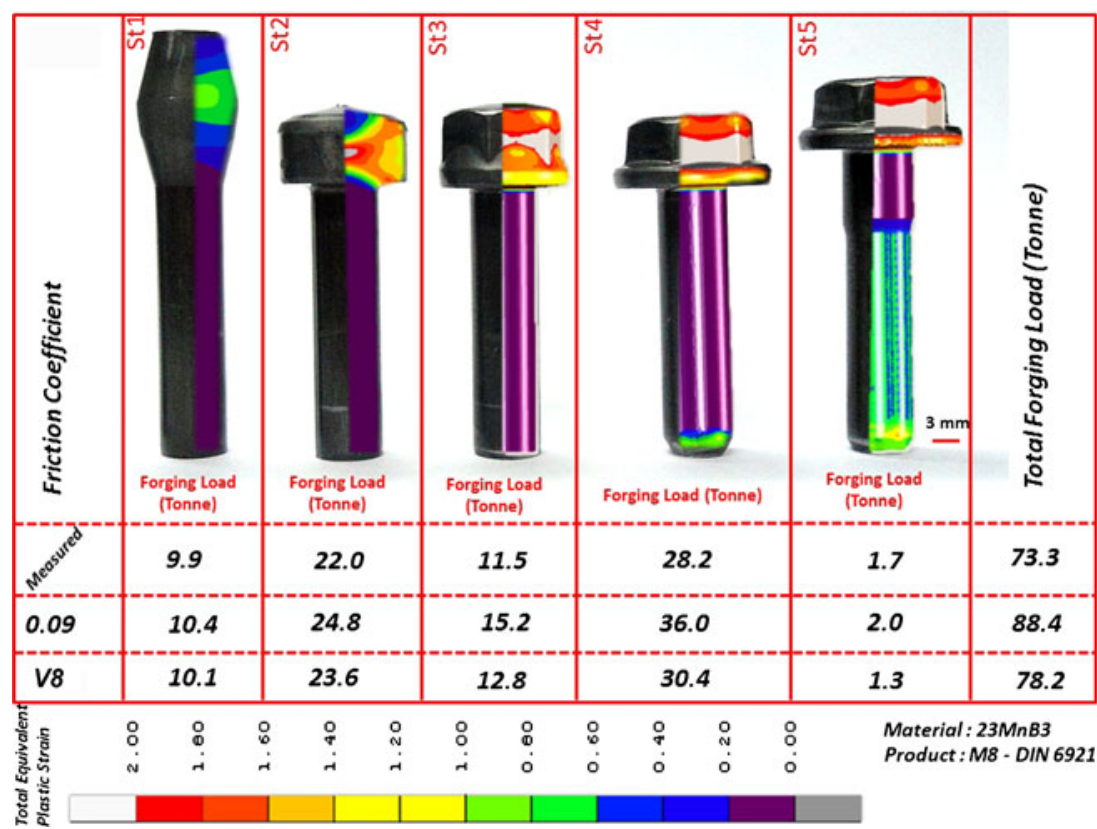

differences between measured and numerically determined average forging loads increase with increasing forging loads. However, the differences are less pronounced with the use of temperature-dependent friction coefficient particularly at increasing forging loads as compared with the use of constant friction coefficient.

Figure 21 shows the variation of the friction coefficient with temperature. The determined set of friction coefficients noted in the same figure is relatively coarse between 200 and 300 and 300 and $400{ }^{\circ} \mathrm{C}$ and may require further numerical and experimental investigation of friction coefficients between these temperatures. In a previous study, the friction coefficient was reported to decrease with phosphate
Fig. 19 The equivalent plastic strain distribution, forging loads, and total forging load of M8 $\times 65$ convex head with square under head forging process

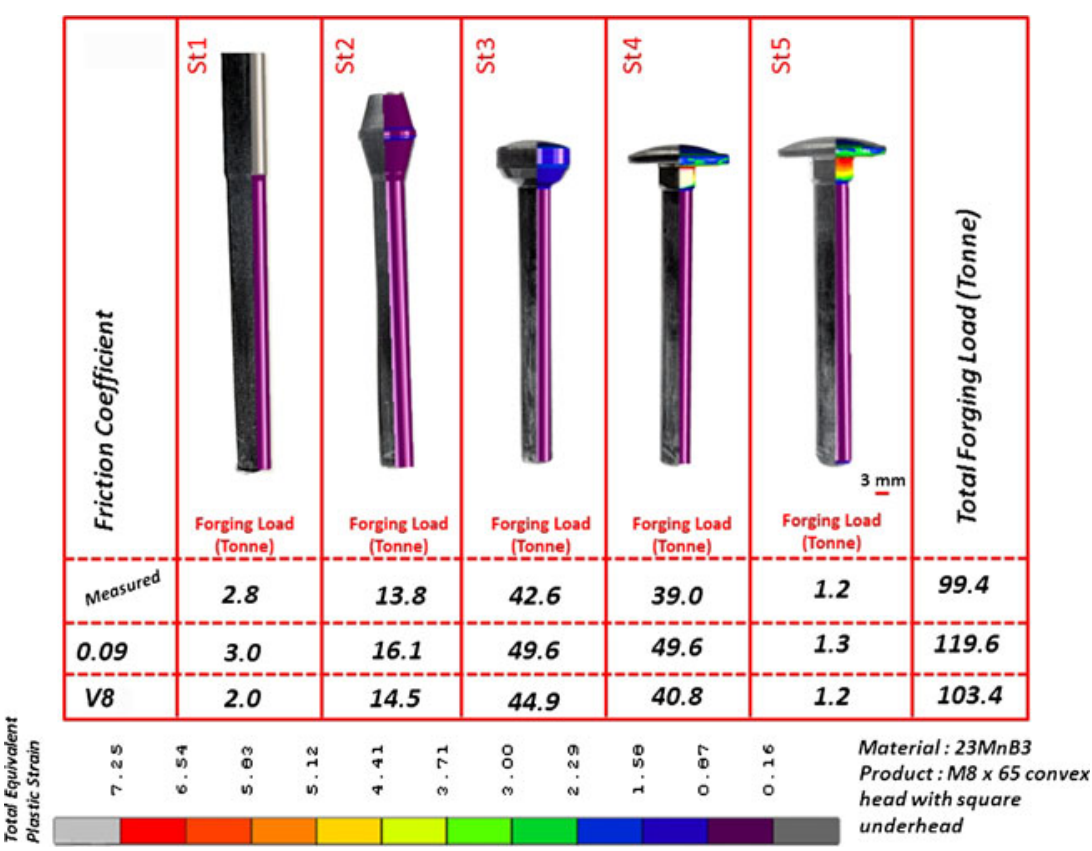




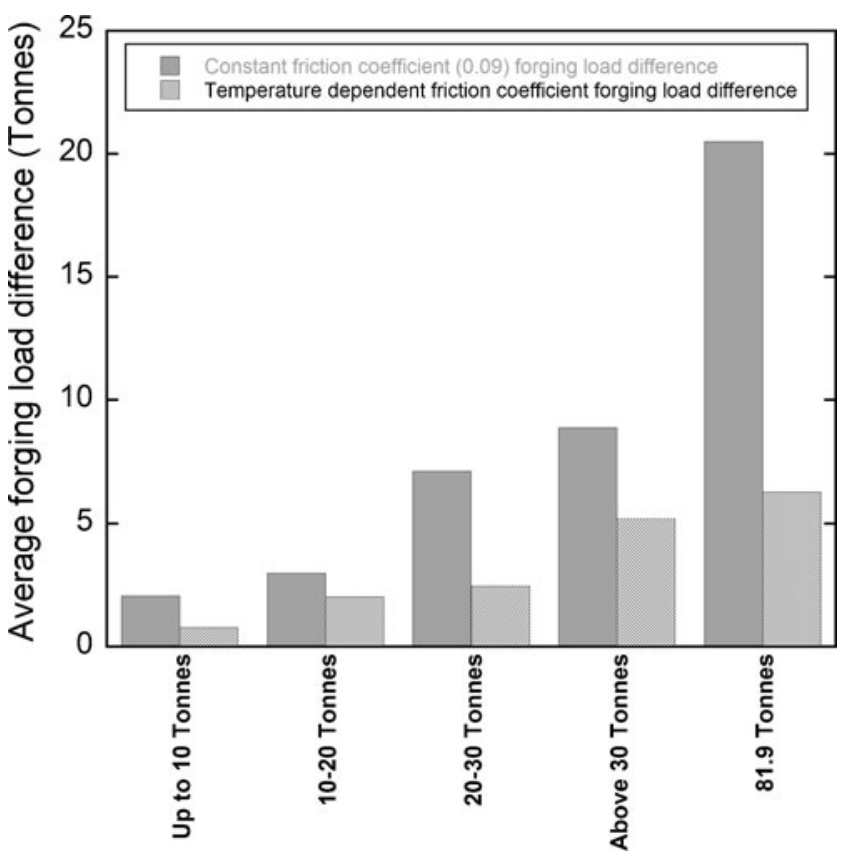

Fig. 20 Average differences between measured and numerically determined forging loads

coating with increasing temperature and attained a minimum value at $250-300{ }^{\circ} \mathrm{C}[12]$. A friction coefficient of 0.04 at $150{ }^{\circ} \mathrm{C}$ was determined previously on a zinc phosphate/soap-coated carbon steel [7], which agrees well with the determined friction coefficient at the same temperature. In another study, the friction coefficients on a zinc phosphate/soap-coated steel at 150,200 , and $250{ }^{\circ} \mathrm{C}$ were reported to be $0.06,0.05$, and 0.04 , respectively [13]. These friction coefficients also well agree with those of the present study; 0.04 and 0.035 between 100 and $200{ }^{\circ} \mathrm{C}$. The increase of the friction coefficient after about $200-300{ }^{\circ} \mathrm{C}$ was further attributed to the decomposition or burning of the lubricant film $[11,12,14]$.

The fidelity of the numerical results of the present study lies in partly the inclusion of the temperature-dependent

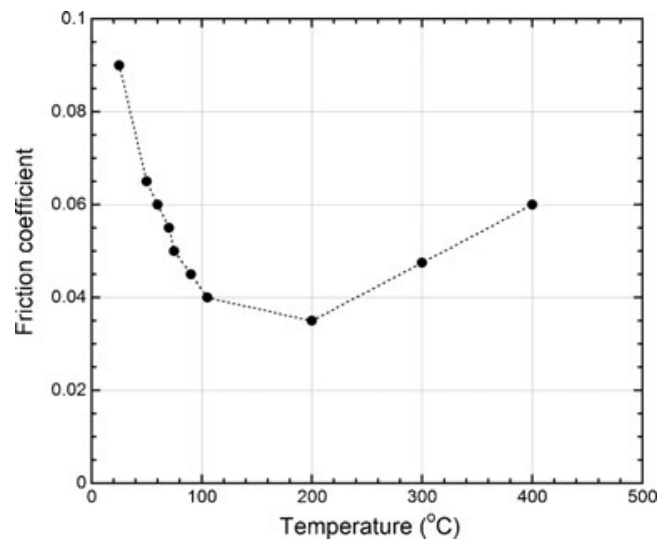

Fig. 21 The numerical variation of the friction coefficient with the forging temperature (V8 set) friction coefficients and piece-wise temperature and strain rate-dependent flow stress material model into the fastener forging simulations and the use of a thermocoupling analysis based on the heat generation by plastic deformation and friction. However, the material thermal property variations with local temperature, pressure, and strain rate and the alterations in the heat conversion parameters with temperature and pressure may unavoidably affect the results. The used friction model further excludes the sticking of the lubricant between tool and workpiece which may eventually invalidates the dry slipping model used [15]. The heat generation factor was measured experimentally for several metals and found to range between 0.8 and 0.9 , when the deformation was slip by the dislocation motion [16]. The factor decreased to a value of 0.6 , when the twinning was the dominant deformation mechanism [17]. In most finite element programs, the factor is default and set to 0.9. Any local alterations in the deformation mechanism may naturally affect the numerical results.

The present experimental and numerical investigations showed that the use of temperature-dependent friction coefficients in thermo mechanical analysis decreases the load values in the order of $10 \%$ as compared with constant friction coefficient and mechanical analysis. This may be advantage in deciding the load limits of the forging presses in the critical operations in which the total force is relatively high and in the level of the load capacity of the press.

\section{Conclusions}

A set of temperature-dependent friction coefficients was developed to increase the accuracy finite element simulations of cold bolt forging. The initially attained friction coefficients at different temperatures were calibrated with the iterations between the experimental and thermomechanical model extrusion test loads. The constant friction coefficient and the determined set of friction coefficients as function of temperature were then implemented to the simulations of the cold bolt-forging processes. Further calibrations and model validations were made based on the temperature measurements of the workpiece in the actual bolt forging of the M $8 \times 20$ circular head and M10 $\times 20$ Inbus DIN 912 bolt. To show the advantages of developed temperature-dependent friction coefficients, the loads of four different bolt-forging processes were compared with the thermomechanical model loads calculated using the constant friction and temperature-dependent friction coefficients. The results showed that variable friction coefficient thermomechanical analysis resulted in relatively lower total forging loads than the constant friction mechanical and thermomechanical analysis. Part of the decrease in total forging load resulted from the use of thermo mechanical 
analysis as compared with mechanical analysis. The use of temperature-dependent friction coefficient in thermomechanical analysis decreased the load values in the order of $10 \%$ as compared with constant friction coefficient and mechanical analysis.

Acknowledgments The authors would like to thank the Scientific and Technical Council of Turkey (TÜBITAK) for the grant \# TEYDEB 3080689 .

\section{References}

1. Hayhurst DR, Chan MW (2005) Determination of friction models for metallic die-workpiece interfaces. Int J Mech Sci 47(1):1-25

2. Behrens A, Schafstall H (1998) 2D and 3D simulation of complex multistage forging processes by use of adaptive friction coefficient. J Mater Process Technol 80-1:298-303

3. Cho HJ, Altan T (2005) Determination of flow stress and interface friction at elevated temperatures by inverse analysis technique. $\mathrm{J}$ Mater Process Technol 170(1-2):64-70. doi:10.1016/ j.jmatprotec.2005.04.091

4. Wang JP, Lin FL, Huang BC, Yun CC (2008) A new experimental approach to evaluate friction in ring test. J Mater Process Technol 197(1-3):68-76. doi:10.1016/j.jmatprotec.2007.06.017

5. Cora ON, Akkok M, Darendeliler H (2008) Modelling of variable friction in cold forging. Proc Inst Mech Eng Part J-J Eng Tribol 222(J7):899-908. doi:10.1243/13506501jet419

6. Tan X, Bay N, Zhang W (2003) Friction measurement and modelling in forward rod extrusion tests. Proc Inst Mech Eng Part J-J Eng Tribol 217(J1):71-82
7. Dubois A, Lazzarotto L, Dubar L, Oudin J (2001) A multi-step lubricant evaluation strategy for wire drawing-extrusion-cold heading sequence. Wear 249(10-11):951-961

8. Saiki H, Ngaile G, Ruan LQ (1997) Influence of die geometry on the workability of conversion coatings combined with soap lubricant in cold forming of steels. J Mater Process Technol 63(13):238-243

9. Bay N (1994) The state of the art in cold forging lubrication. J Mater Process Technol 46(1-2):19-40. doi:10.1016/0924-0136 (94) $90100-7$

10. Farias MCM, Santos CAL, Panossian Z, Sinatora A (2009) Friction behavior of lubricated zinc phosphate coatings. Wear 266(7-8):873-877. doi:10.1016/j.wear.2008.10.002

11. Weymueller R, Carl. (1962) Source book on cold forming; cold extrusion of steels: its promises and problems; American Society for Metals

12. Ruan LQ, Saiki H, Marumo Y, Imamura Y (2005) Evaluation of coating-based lubricants for cold forging using the localised roddrawing test. Wear 259:1117-1122. doi:10.1016/j.wear.2005.02.103

13. Ngaile G, Saiki H, Ruan LQ, Marumo Y (2007) A tribo-testing method for high performance cold forging lubricants. Wear 262(56):684-692. doi:10.1016/j.wear.2006.08.009

14. Steenberg T, Olsen JS, Christensen E, Bjerrum NJ (1999) Estimation of temperature in the lubricant film during cold forging of stainless steel based on studies of phase transformations in the film. Wear 232(2):140-144. doi:10.1016/s0043-1648(99)00137-4

15. Tan X (2002) Comparisons of friction models in bulk metal forming. Tribol Int 35(6):385-393. doi:10.1016/S0301-679X (02)00020-8

16. Mason JJ, Rosakis AJ, Ravichandran G (1994) On the strain and strain rate dependence of the fraction of plastic work converted to heat: an experimental study using high speed infrared detectors and the Kolsky bar. Mech Mater 17(2-3):135-145

17. Meyers MA (1994) Dynamic behavior of materials. Wiley, New York 